\title{
Maternal Obesity and the Fetal Origins of the Metabolic Syndrome
}

\author{
Jwan Rkhzay-Jaf • Jacqueline F. O'Dowd • \\ Claire J. Stocker
}

Published online: 14 August 2012

(C) The Author(s) 2012. This article is published with open access at Springerlink.com

\begin{abstract}
Over recent decades there has been a rapid rise in metabolic disorders throughout the world. Whilst lifestyle and societal habits have contributed to the obesity epidemic, there is now increasing evidence that the early developmental environment of an infant can play a pivotal role in the 'programming' of an adverse physiological phenotype in later life. Clinical evidence highlights that maternal over-nutrition and/ or obesity during pregnancy presents not only adverse effects on maternal health, but also persistent and deleterious effects in the developing child. Animal models are providing essential information into the underlying cellular and molecular mechanisms that contribute to this adverse phenotype. The use of this information will aid our understanding of the programming signals related to maternal and paternal over-nutrition and the improved healthcare for both mother and infant.
\end{abstract}

Keywords Maternal overnutrition · Developmental programming · Type 2 diabetes $\cdot$ Cardiovascular disease . Obesity

\section{Introduction}

Overweight and obesity are considered to be the fifth leading risks for global deaths with at least 2.8 million adults dying each year as a result. In 2008, 1.5 billion adults aged 20 years and older were overweight; of these over 200 million men and

J. Rkhzay-Jaf · J. F. O’Dowd · C. J. Stocker $(\bowtie)$

Clore Laboratory, University of Buckingham,

Hunter Street,

Buckingham MK18 1EG, UK

e-mail: Claire.stocker@buckingham.ac.uk

J. Rkhzay-Jaf

e-mail: Jwan.Rkhzay-Jaf@buckingham.ac.uk

J. F. O'Dowd

e-mail: Jacqueline.O'Dowd@buckingham.ac.uk nearly 300 million women were obese. In addition, $44 \%$ of the diabetes, $23 \%$ of the ischemic heart disease. and between $7 \%$ and $41 \%$ of certain cancer burdens are attributable to overweight and obesity. Its growing prevalence is therefore one of the major health care issues of this century [1]. In 2010, 43 million children under 5 were estimated to be overweight and childhood obesity tracks strongly to adolescent and adulthood obesity [2]. Childhood overweight and obesity, once considered a problem of high-income countries, are now rising in low and middle income countries, particularly in urban areas with close to 35 million overweight children living in developing countries and 8 million in developed countries. Of particular concern is the growing prevalence of obesity in women of child-bearing age, as not only does this have health implications for them, but also there is increasing evidence that obesity during pregnancy and lactation can have long term effects on the health of the child [3, 4].

Genome-wide association studies have given insight into the importance of an individual's genetic makeup and their predisposition to metabolic disease [5]. However, the dramatic rise in obesity indicates that this must be driven by environmental factors that affect dietary and physical activity patterns. In addition, it is now well recognized that the phenotype of an individual can be determined by its early developmental environment and in particular by the nutritional status of the mother. Such studies have led to the proposals of 'developmental programming' that describe how the conditions presented during a critical window of development can lead to the permanent programmed alterations in a physiological process.

\section{Early Life Programming}

Epidemiological data worldwide has revealed a relationship between birth weight and the risk of developing cardiovascular and metabolic disease. Some of the earliest studies 
focused on the relationship between maternal under-nutrition and an infant being small for gestational age. Forsdahl proposed that poverty in early childhood could program the infant for low energy intake. If such an individual then consumed modern day, high energy-dense foods, this could be one reason why in recent times there is an increased incidence of cardiovascular disease [6]. Men exposed in utero to the Dutch Hunger Winter famine were more obese at age 19 if they were exposed to the famine during the first half of their mother's pregnancy. In contrast, those who were exposed to the famine during the last trimester of pregnancy and in early postnatal life had reduced obesity [7]. Studies in Hertfordshire in the UK showed that men who were the smallest at birth were at increased risk of heart disease [8] and were more likely to be glucose intolerant or type 2 diabetic [9, 10]. These studies formed the basis of the 'Thrifty phenotype hypothesis' [11] that proposed that poor fetal nutrition leads to metabolic adaptations to maximize the chances of survival in conditions of on-going nutritional deprivation. Such adaptations would be beneficial if exposed to poor conditions after birth, but would not be suited if the postnatal environment provided plentiful nutrition, resulting in an increased risk of developing features of the metabolic syndrome. Other hypotheses have since been proposed to understand the observation that fetal nutrition leads to the permanent programming of metabolism and a maladapted adult phenotype if the fetus is born into conditions where the early and adult environments are 'mismatched'. Of more relevance, however, to modern society in which maternal nutritional excess is more common, is the 'developmental over-nutrition hypothesis'.

\section{Clinical Impact of Maternal Diet and Maternal Obesity and Postnatal Overnutrition}

The prevalence of obesity is highest among children of obese parents [12]. Children of obese mothers are more at risk of overweight or obesity than those of obese fathers [13-15]. Maternal pre-pregnancy overweight has also been found to be as an independent risk factor for infant overweight and abdominal obesity [16]. Moreover, there are associations between pregnant maternal body mass index (BMI) and offspring BMI, adiposity, and insulin resistance [17-19], and also between maternal weight gain during pregnancy and offspring adiposity [20•]. Obesity in pregnancy is strongly associated with the development of gestational diabetes and there are many reports of associations between maternal diabetes and offspring diabetes [21, 22], and offspring obesity [23]. Recent clinical guidelines have reported that almost 1 in 5 UK pregnant women are now obese, which is a serious concern not only because of adverse pregnancy outcome, particularly gestational diabetes and fetal macrosomia, but also because of the reported associations with childhood risk of obesity, and insulin resistance. But possibly of greater concern are reports that moderate weight gain between successive pregnancies could result in an increase in birth weight [24]. Better-nourished mothers give birth to better nourished mothers-to-be, resulting in transgenerational obesity [25]. The interpretation is that susceptibility to obesity, type 2 diabetes, and cardiovascular disease is partly programmed by the environment during early pre and post natal life.

The early postnatal environment is a key time point for developmental programming to occur. Since physiological systems continue to develop and mature after birth, overnutrition in this period will have considerable impact. Rapid postnatal growth following maternal malnutrition leads to obesity in later life and carries the highest risk of insulin resistance. Some reports suggest that rapid growth in the first few weeks of postnatal life is particularly disadvantageous [26], while other reports indicate that rapid growth of low birth weight infants in later childhood also increases their risk of obesity [27]. It is now known that rapid growth in itself is associated with an increased risk of elevated blood pressure, cardiovascular disease and type 2 diabetes, as well as a disproportionately high rate of fat deposition [28]. During this period dietary composition can affect growth patterns of the infant. Nutrient-enriched formula feeding is often used as an alternative or supplemental to breast feeding and can accelerate infant growth [26, 29]. Formula feeding increases the risk of obesity in childhood [26] as well as high cholesterol in adulthood [30] compared with breast feeding. Bottle-fed infants have higher total energy and protein intakes than breast-fed infants. So one possible explanation is that the plane of nutrition during the suckling period is a strong determinant for subsequent appetite regulation. Breastfed infants appear to have a greater ability to regulate food intake both when breastfeeding [31] and when eating solid food. Furthermore, breastfed infants show a reduced growth rate compared with formula-fed infants, are leaner, and are less susceptible to developing obesity, cardiovascular risk factors and hypertension [32].

The identification of the factors in the maternal environment that mediate the effects of maternal obesity and diet is of key importance to the development of clinical intervention strategies. Maternal hyperglycemia during pregnancy was thought to be one of the most important predictive factors of infant obesity and metabolic disease [33]. Now it is recognized that other maternal parameters associated with obesity and/or over-nutrition during pregnancy are involved including hyperinsulinaemia, hypertriglyceridaemia, and hyperleptinaemia. Maternal hyperglycaemia stimulates fetal insulin synthesis and increases fetal adiposity, which may permanently influence fetal adipocyte mass [34]. Maternal triglycerides, which are elevated in obese and insulin resistant women, will not cross the placenta but are 
hydrolysed by placental lipases [35] and may affect fetal fuel supply. Moreover, several reports have highlighted correlations between maternal insulin resistance, maternal plasma triglycerides, and offspring adiposity [14, 36]. Other studies in pregnant women and non-human primates have implicated the inflammatory state associated with maternal obesity as causing persistent influences on offspring metabolic function [37, 38]. Neonatal hyperinsulinaemia has been associated with increased adiposity in the infant [39].

\section{Animal Models of Developmental Programming}

Whilst epidemiological studies are essential for establishing correlations between maternal nutritional status and offspring health, they are often complicated by genetic or environmental variables that confound correlation analysis. Animal models have therefore provided an invaluable insight into the underlying mechanisms of developmental programming because they allow intervention studies and also because genetic background can be strictly controlled. Such studies show strong parallels with the human observational studies, supporting a causal relationship between maternal obesity and offspring adiposity, glucose tolerance, insulin sensitivity, and cardiovascular disease. The majority of research has focused on sheep and rodents but rodents present a better model as they develop features of metabolic syndrome within months and are therefore more feasible for study. Non-human primates offer advantages because of the similarities of their developmental patterns to humans; however long gestation periods and high costs make them less available. When interpreting these studies, it is important to recognize that dietary manipulation in itself could introduce complications, as increasing one component could require the reduction of another. Offspring of high fat-fed dams have increased adiposity, insulin resistance, and hypertension [40], but here increasing the fat content reduces the carbohydrate content [41, 42], or protein content [43]. Modern day western diets are high in sugar as well as in fat and these obesogenic diets are available commercially. The offspring from these dams are hyperphagic, insulin resistant, glucose intolerant and hypertensive [41, 42]. The maternal 'junk food' diet also produces offspring with increased adiposity and hyperphagia for junk food after weaning [44]. All these diets have provided good evidence that maternal nutritional excess can contribute to this relationship [41-46].

Animal models have been used to specifically investigate the programming role of fuels and hormones that can pass directly from mother to fetus. Models of maternal diabetes have focussed on its effects on the pancreas leading to neonatal hyperinsulinemia and on the developing hypothalamus, leading to increased food intake and offspring obesity [47]. In the mouse, insulin and leptin were raised both on day 18 of gestation and at the end of lactation when fed an obesogenic diet [41]. This was associated with early elevated leptin and resistance to the action of leptin to reduce food intake in the offspring [48]. In the sheep increased placental fatty transporters has been associated with higher fetal triglyceride levels [49], enhanced cytokine expression in the placenta [50], and upregulated lipogenic genes in the adipose [51]. Similarly in mice, a high fat in-utero environment can increase the fetal triglyceride profile [52]. As in large for gestational age human fetuses, changes in placental morphology in overfed non-human primates have been observed [53], associated with increased nutrient delivery to the fetus for example of free fatty acids [54].

Rodent models have been used to investigate the effects of postnatal over-nutrition. The majority of studies have manipulated litter size post birth to alter the nutritional exposure. Reducing litter size results in hyperphagia, hyperinsulinemia, and cardiovascular risk in the offspring [55]; others report that rearing diet-induced obese rats in large litters protects against obesity [56]. Cross fostering has also been used to increase an infant's nutritional plane in the suckling period and program susceptibility to obesity in adult life [57]. In these models pups suckled in large litters or whose dams are under-nourished are resistant to the development of obesity even when the pups are given a high fat diet from weaning [58]. In models of gestational diabetes, hyperglycemia during suckling results in obesity and insulin resistance in the infant in later life [59].

Despite the wealth of data from a variety of models, a common offspring phenotype of increased adiposity, hyperphagia, insulin resistance, and hypertension is emerging (Fig. 1). The programming of obesity is a multifactorial process but similar mechanistic pathways are being revealed.

\section{Maternal Diet vs Maternal Obesity}

In human studies it is difficult to dissect out the effects of maternal obesity from those of an obesogenic diet, but this can be addressed in animal models. A high fat diet throughout pregestation, gestational period, or postnatally will have different effects depending on the time the diet is introduced. The importance of maternal obesity independent of a difference in diet is supported by the observation that chow-fed wild-type offspring of the leptin receptor deficient $(d b / d b)$ dam are obese and hyperinsulinaemic [60]. In contrast, there is evidence for the effects of maternal diet independent of increases in maternal weight. In studies where rat dams were fed a cafeteria-style or high fat diet initiated after conception so that during pregnancy and lactation the dams were not obese [43, 61], their offspring developed increased adiposity, hyperglycaemia, and hyperinsulinaemia. Most models however have studied the offspring from dams fed an obesogenic or high fat diet throughout pregnancy and lactation, leading to increased adiposity of offspring at weaning and glucose intolerance [41, 42]. It is now emerging that the postnatal diet can modify the 
Fig. 1 Common mechanistic pathways of developmental programming as a result of maternal over nutrition

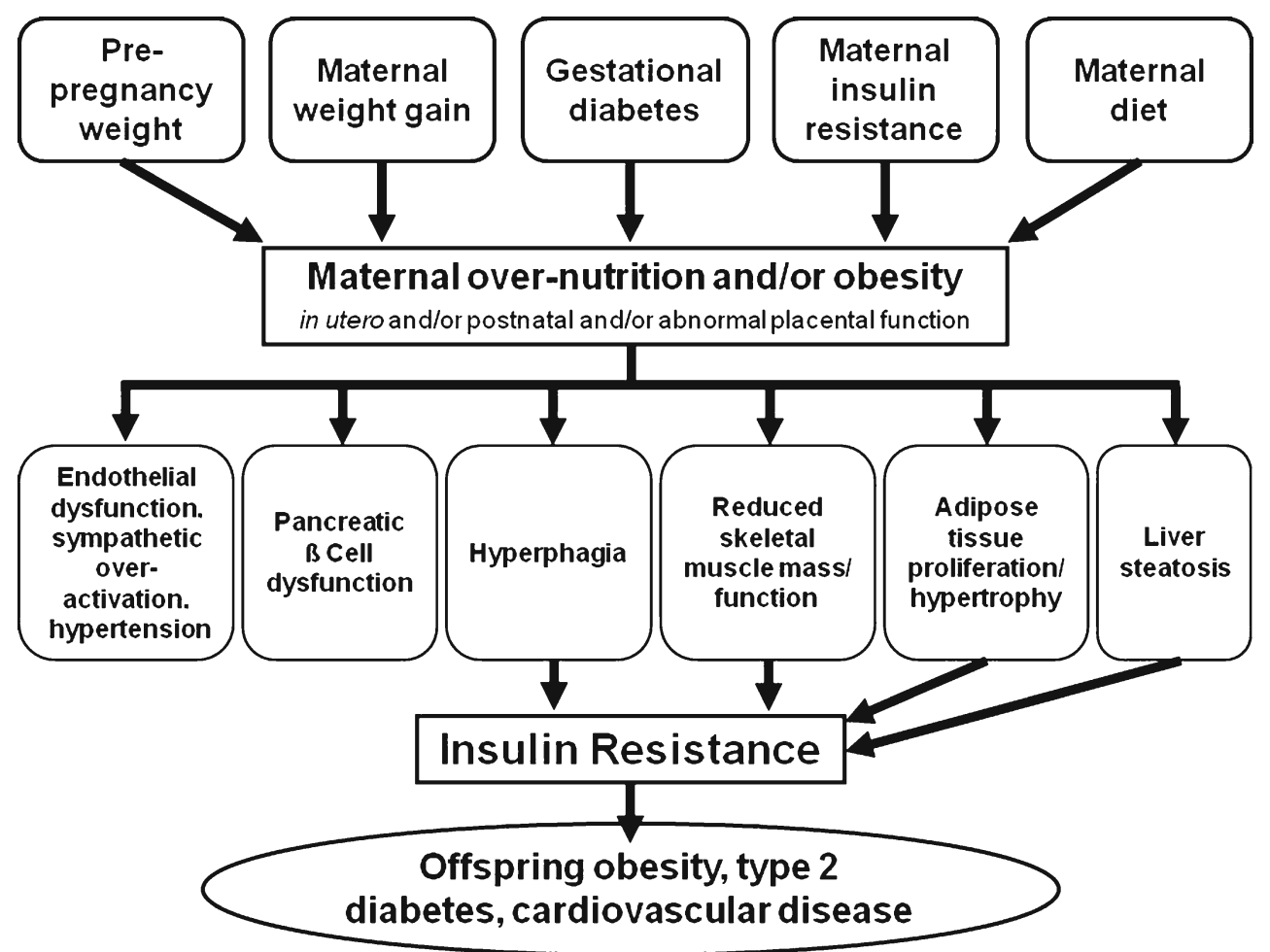

programming of maternal obesity in utero. When offspring were exposed to maternal obesity during gestation and lactation and then maintained on a high fat diet after weaning, they rapidly gained weight and adipose mass [62]. Similarly female pups fed a formula diet immediately after birth, were obese, and obesity was then transmitted to the next generation even if these mice were maintained on a chow diet [63]. Maternal obesity and diet have been reported to have different effects on fetal growth. By varying the exposure of the dam either before gestation, resulting in maternal obesity or during gestation, it was reported that the obese in utero environment resulted in reduced fetal weight, whilst the obese gestational diet caused abnormal placental growth [64].

\section{Developmental Programming Mechanisms}

The animal models of nutritional programming demonstrate common mechanisms of adult disease susceptibility with man, including alterations in appetitive behavior, accelerated loss of glucose tolerance and insulin sensitivity, changes in thermogenic capacity, and altered percentage fat mass and distribution.

\section{Central Mechanisms}

The hypothalamus plays an essential role in the control of energy balance; its nuclei continue to differentiate postnatally [65] and hypothalamic neuropeptides can be permanently altered by the maternal and fetal dietary environment.
Offspring of dams fed a fat rich diet are hyperphagic soon after weaning and show exaggerated feeding responses to orexigenic peptides and blunted signalling to satiety peptides. This could be one explanation for the observed changes in appetitive behavior [66] and food preferences [45] in the offspring [49]. Both leptin and insulin regulate long-term feeding behavior. Leptin acts on the arcuate nucleus in the hypothalamus to reduce hunger and increase energy expenditure and following administration to postnatal mice, leptin has been shown to deactivate orexigenic neuropeptide Y (NPY) and activate anorectic pro-opiomalanocortin neurones [67]. Rat pups from small litters show increased NPY expression and a reduced responsiveness to leptin [68, 69]. Leptin also plays a role in the neonatal development of the hypothalamus. Neuronal connection pathways in the arcuate nucleus are permanently disrupted in the leptin deficient obese mouse. Leptin treatment in adulthood is unable to reverse this neuro-anatomical defect [70] however treatment during the perinatal period completely restores the density and length of these neuronal projections [71]. During the early postnatal period there is a surge in circulating plasma leptin, independent of fat mass, which may serve as a key developmental signal to the hypothalamus to influence subsequent food intake and body weight [72]. Therefore any changes in leptin levels or leptin action [73] during this critical period may cause permanent alterations in the neuronal circuitry [74]. The maternal environment can influence the precise timing and hence the effect of this surge. Offspring of rat dams fed an obesogenic diet have an amplified and prolonged neonatal 
leptin surge, with attenuated leptin signalling before the onset of hyperphagia [48]. Similarly in sheep, whose lambs are born at an equivalent level of maturity to humans, a premature leptin peak is observed accompanied by increased appetite [75]. Therefore there may be a beneficial role for leptin in the reversal of the metabolic programming of maternal obesity, as it does in offspring of undernourished and normal dams where the leptin surge is reduced, both during gestation and lactation [76] or during suckling alone [77].

A neurotrophic role for insulin in hypothalamic development is now emerging. Suboptimal or neonatal hyperinsulinemia may result in the malformation of hypothalamic structures and their role in the control of food intake. The hyperphagia seen in models of maternal obesity may also be the consequence of dysregulated reward pathways. Food preferences and the motivation to eat highly palatable foods have been associated with the altered expression of the mesolimbic dopamine and opioid reward pathways [78].

\section{Peripheral Mechanisms}

Programmed alterations in peripheral tissues such as muscle, adipose, and liver affect energy balance and glucose homeostasis. A progressive impairment of glucose homeostasis is highlighted in many animal models of maternal obesity. Many of the changes are due to changes in insulin sensitivity of the peripheral tissues resulting from a defect in insulin action downstream of the receptor [79]. In models of maternal obesity insulin resistance likely precedes beta cell failure [63]. The skeletal muscle is a major insulin sensitive tissue and abnormal development and function has been reported in a number of models [41]. Offspring of over-nourished dams exhibit reduced muscle cell proliferation and intramuscular lipid accumulation [44]. The maternal diet influences adipogenesis and the programming of adipocyte morphology and metabolism, with changes in the pattern of expression of key regulatory and functional genes, which are important determinants of fat distribution and accumulation. Persistent alterations in the expression of proteins involved in adipocyte development and lipolysis could result in permanent influences on adipocyte proliferation and hypertrophy [80]. An increased fat mass may be a compensatory mechanism to ensure that excess lipids are stored in adipocytes rather than ectopically; however an increase in adiposity results in increased insulin resistance and inflammatory responses. The liver plays a pivotal role in metabolism, elevated triglyceride levels and fatty liver have been associated with maternal overnutrition [41] as well as the upregulation of genes involved in hepatic lipid biosynthesis $[62,81]$.

\section{Cardiovascular System}

Studies of pregnant women and their infants found that those who exceeded the recommended weight gain during pregnancy give birth to children, who at age 9 presented with increased systolic blood pressure, C-reactive protein, lower high-density lipoprotein cholesterol, and increased BMI [82]. Rodent models of maternal obesity have shown that the offspring have increased systolic blood pressure, elevated triglyceride and cholesterol levels [41]. Similarly, offspring of normally fed dams cross-fostered and suckled by high fat-fed dams developed hypertension similar to those exposed to high fat during pregnancy [40]. These rats display endothelial dysfunction as well as abnormal aortic elasticity [83]. The consistently elevated blood pressure in offspring of obese dams was attributed to sympathetic over-activation, with altered heart rate variability and abnormal baroreceptor responsiveness [84]. As with insulin resistance, fat feeding in the absence of maternal obesity led to altered sympathetic control of cardiovascular function and hypertension [85].

\section{Endocrine Pancreas}

In models of maternal under-nutrition reductions of beta cell mass and insulin content are associated with a reduction in insulin secretion. In contrast, offspring of dams fed a high fat diet through gestation alone showed altered neonatal islets with increased alpha cell number and size and with an opposite effect on the beta cell [86]. Offspring of obese dams fed an obesogenic diet throughout gestation and lactation were hyperinsulinemic at 3 months of age [41], which was associated with increased pancreatic insulin content, increased islet number and increased beta cell mass in early life [87], which declined with age due to persistent stimulation [63]. Similar observations were recorded in sheep where at lambing reduced offspring beta cell numbers was associated with an increase in beta cell apoptosis [88]. In a model of paternal high fat feeding impaired beta cell function in female offspring early in life was associated with reduced islet area and insulin secretion following a glucose challenge [89•].

\section{Molecular Mechanisms}

A number of underlying mechanisms have been investigated in models of developmental programming. Markers of oxidative stress have been associated with obesity and diabetes and recent studies have suggested that reactive oxygen species production may be a key event preceding the onset of obesity in response to maternal nutrition in the placenta [90], fetal skeletal muscle [91] and fetal liver [53]. Interestingly, antioxidant supplementation to dams fed a western diet was able to reduce oxidative stress, inflammation, and adiposity in the embryos [92•]. The mitochondrion is particularly sensitive to early developmental programming and mutations in mitochondrial DNA persist through generations influencing long- 
term cellular functions including adaptive thermogenesis. Mitochondrial dysfunction has been reported as early as embryogenesis in obese mothers, with these embryos having increased mitochondrial membrane potential, higher levels of oxidative phosphorylation and increased reactive oxygen species production [93]. Disruptions in the electron transport chain have also been demonstrated in skeletal muscle and liver of offspring from over-nourished mothers [79, 94].

Epigenetic dysregulation has been reported to mediate the effects of early nutrition on adult disease susceptibility, of which DNA methylation is the most common mechanism studied. Methyl donors are sourced from the diet and methylation patterns are established during development. Therefore methyl donor imbalances could alter epigenetic patterns and increase an individual to metabolic disease in later life [95•]. In the pancreas of rat pups reared in small litters, an epigenetic alteration of the insulin 2 gene reduced its expression and was associated with reduced glucose stimulated insulin secretion [96]. Hypermethylation of the hypothalamic POMC promoter was observed in this model [97]. In aortic endothelial cells, hyperglycemia results in the activation of nuclear factor $\mathrm{kB}$ increasing its expression. Changes such as these are clearly important when considering that diabetes is a major independent risk factor for atherosclerotic cardiovascular disease [98]. Data is emerging on the transgenerational effects of maternal obesity and diet, with maternal diet influencing body length and insulin sensitivity in second and third generation mice [99]. The transmission solely through the paternal lineage suggests epigenetic programming of the sperm epigenome [89•]. Therefore these studies highlight how maternal nutrition can influence health of future generations and may explain the rapid increase in obesity prevalence through generations.

\section{Future Direction and Clinical Interventions}

Evidence to date highlights the importance of the obese preand postnatal environment and the consequences of developmental programming on an infant's susceptibility to metabolic disorders in later life. Clearly, the use of animal models has been extremely useful for dissecting the contributory factors and critical time windows. Over the next few years, it is likely that mechanisms will be identified by which early life programming determines the set point of energy balance and how the numerous brain circuits and peripheral endpoints are integrated and regulated so that energy expenditure and energy intake are matched. Improved nutritional awareness of the mother and father are essential. Dietary restriction and weight loss prior to pregnancy are proven strategies to improve infant health outcome, but therapeutic interventions will likely be of use in obese pregnant women. Understanding the programming signals related to maternal over-nutrition will allow the improved healthcare of both mother and infant.
Disclosure No potential conflicts of interest relevant to this article were reported.

Open Access This article is distributed under the terms of the Creative Commons Attribution License which permits any use, distribution, and reproduction in any medium, provided the original author(s) and the source are credited.

\section{References}

Papers of particular interest, published recently, have been highlighted as:

- Of importance

1. Franks PW, Hanson RL, Knowler WC, Sievers ML, Bennett PH, Looker HC. Childhood obesity, other cardiovascular risk factors and premature death. N Engl J Med. 2010;362:485-93.

2. Wardle J, Brodersen NH, Cole TJ, Jarvis MJ, Boniface DR. Development of adiposity in adolescence: five year longitudinal study of an ethnically and socioeconomically diverse sample of young people in Britain. BMJ. 2006;332:1130-5.

3. Nelson SM, Matthews P, Poston L. Gestational weight gain: influences on the longterm health of the child. Curr Opin Clin Nutr Metab Care. 2012;15:252-7.

4. Alfaradhi MZ, Ozanne SE. Developmental programming in response to maternal overnutrition. Front Genet 2011, 2 article 27.

5. Frayling TM. Genome-wide association studies provide new insights into type 2 diabetes aetiology. Nat Rev Genet. 2007;8:65762.

6. Forsdahl A. Are poor living conditions in childhood and adolescence an important risk factor for arteriosclerotoc heart disease? $\mathrm{Br}$ J Prev Soc Med. 1977;31:91-5.

7. Ravelli GP, Stein ZA, Susser MW. Obesity in young men after famine exposure in utero and early infancy. N Engl J Med. 1976;295:349-53.

8. Barker DJ, Osmond C. Diet and coronary heart disease in England and Wales during and after the second world war. J Epidemiol Community Health. 1986;40:37-44.

9. Hales CN, Barker DJ, Clark PM, Cox LJ, Fall C, Osmond C, Winter PD. Fetal and infant growth and impaired glucose tolerance at age 64. BMJ. 1991;303:1019-22.

10. Barker DJ, Hales CN, Fall CH, Osmond C, Phipps K, Clark PM. Type 2 (non-insulin-dependent) diabetes mellitus, hypertension and hyperlipidaemia (syndrome $\mathrm{X}$ ): relation to reduced fetal growth. Diabetologia. 1993;36:62-7.

11. Hales CN, Barker DJ. Type 2 (non-insulin-dependent) diabetes mellitus: the thrifty phenotype hypothesis. Diabetologia. 1992;35:595-601.

12. Whitaker RC, Wright JA, Pepe MS, Seidel KD, Dietz WH. Predicting obesity in young adulthood from childhood and parental obesity. N Engl J Med. 1997;337:869-73.

13. Lawlor DA, Smith GD, O'Callaghan M, Alati R, Mamun AA, Williams GM, Najman JM. Epidemiologic evidence for the fetal over-nutrition hypothesis: findings from the mater-university study of pregnancy and its outcomes. Am J Epidemiol. 2007;165:41824.

14. Catalano PM, Farrell K, Thomas A, Huston-Presley L, Mencin P, de Mouzon SH, et al. Perinatal risk factors for childhood obesity and metabolic dysregulation. Am J Clin Nutr. 2009;90:1303-13.

15. Whitaker KL, Jarvis MJ, Beeken RJ, Boniface D, Wardle J. Comparing maternal and paternal intergenerational transmission 
of obesity risk in a large population-based sample. Am J Clin Nutr. 2010;91:1560-7.

16. Pirkola J, Pouta A, Bloigu A, Hartikainen AL, Laitinen J, Järvelin $\mathrm{MR}$, et al. Risks of overweight and abdominal obesity at age 16 years associated with prenatal exposures to maternal prepregnancy overweight and gestational diabetes mellitus. Diabetes Care. 2010;33:1115-21.

17. Whitaker RC. Predicting preschooler obesity at birth: the role of maternal obesity in early pregnancy. Pediatrics. 2004;114:e29-36.

18. Koupil I, Toivanen P. Social and early-life determinants of overweight and obesity in 18-year old Swedish men. Int J Obes. 2008;32:73-81.

19. Mingrone G, Manco M, Mora ME, Guidone C, Iaconelli A, Gniuli $\mathrm{D}$, et al. Influence of maternal obesity on insulin sensitivity and secretion in offspring. Diabetes Care. 2008;31:1872-6.

20. • Reynolds RM, Osmond C, Philips DI, Godfrey KM. Maternal BMI, parity and pregnancy weight gain: influences on offspring adiposity in young adulthood. J Clin Endocrinol Metab. 2010;95:5365-9. Clinical study highlighting relationship between maternal weight and maternal weight gain and offspring susceptibility.

21. Dabelea D. The predisposition to obesity and diabetes in offspring of diabetic mothers. Diabetes Care. 2007;30:S169-74.

22. Vohr BR, Boney CM. Gestational diabetes: the forerunner for the development of maternal and childhood obesity and metabolic syndrome? J Matern Fetal Neonatal Med. 2008;21:149-57.

23. Poston L. Developmental programming and diabetes. The human experience and insight from animal models. Best Pract Res Clin Endocrinol Metab. 2010;24:541-52.

24. Catalano PM. Obesity and pregnancy, the propagation of a viscous cycle? J Clin Endocrinol Metab. 2003;88:3505-6.

25. Villamor E, Cnattingius S. Interpregnancy weight change and risk of adverse pregnancy outcomes: a population-based study. Lancet. 2006;368:1164-70.

26. Stettler N, Stallings VA, Troxel AB, Zhao J, Schinnar R, Nelson $\mathrm{SE}$, et al. Weight gain in the first week of life and overweight in adulthood: a cohort study of European American subjects fed infant formula. Circulation. 2005;111:1897-903.

27. Ong KK. Size at birth, postnatal growth and risk of obesity. Horm Res. 2006;65:65-9.

28. Ekelund U, Ong KK, Linne Y, Neovius M, Brage S, Dunger DB, et al. Association of weight gain in infancy and early childhood with metabolic risk in young adults. J Clin Endocrinol Metab. 2007;92:98-103.

29. Singhal A, Kennedy K, Lanigan J, Clough H, Jenkins W, EliasJones A, et al. Nutrition in infancy and long-term risk of obesity: evidence from 2 randomised controlled trials. Am J Clin Nutr. 2010;92:1133-44.

30. Singhal A, Cole TJ, Fewtrell M, Lucas A. Breastmilk feeding and lipoprotein profile in adolescents born preterm: follow-up of a prospective randomised study. Lancet. 2004;363:1571-8.

31. Dewey KG, Heinig MJ, Nommsen LA, Peerson JM, Lönnerdal B. Breast-fed infants are leaner than formula-fed infants at $1 \mathrm{y}$ of age: the DARLING study. Am J Clin Nutr. 1993;57:140-5.

32. Singhal A, Cole TJ, Fewtrell M, Lucas A. Is slower early growth beneficial for long-term cardiovascular health? Circulation. 2004;109:1108-13.

33. Hillier TA, Pedula KL, Schmidt MM, Mullen JA, Charles MA, Pettitt DJ. Childhood obesity and metabolic imprinting: the ongoing effects of maternal hyperglycemia. Diabetes Care. 2007;30:2287-92.

34. HAPO Study Co-operative Research Group. Hyperglycaemia and Adverse Pregnancy Outcome (HAPO) Study: association with neonatal anthropometrics. Diabetes. 2009;58:453-9.

35. Herrera E, Amusquivar E. Lipid metabolism in the fetus and the newborn. Diabetes Metab Res Rev. 2000;16:202-10.

36. Hamilton JK, Odrobina E, Yin J, Hanley AJ, Zinman B, Retnakaran R. Maternal insulin sensitivity during pregnancy predicts infant weight gain and adiposity at 1 year of age. Obesity. 2010;18:340-6.

37. Nelson SM, Matthews P, Poston L. Maternal metabolism and obesity: modifiable determinants of pregnancy outcome. Human Reprod Update. 2010;16:255-75.

38. Grayson BE, Levasseur PR, Williams SM, Smith MS, Marks DL, Grove KL. Changes in melanocortin expression and inflammatory pathways in fetal offspring of non-human primates fed a high fat diet. Endocrinology. 2010;151:1622-32.

39. Silverman BL, Metzger BE, Cho NH, Loeb CA. Impaired glucose tolerance in adolescent offspring of diabetic mothers. Relationship to fetal hyperinsulinism. Diabetes Care. 1995;18:611-7.

40. Khan IY, Dekou V, Douglas G, Jensen R, Hanson MA, Poston L, et al. A high fat diet during pregnancy or suckling induces cardiovascular dysfunction in adult offspring. Am J Physiol Regul Integr Comp Physiol. 2005;288:R127-33.

41. Samuelsson AM, Matthews PA, Argenton M, Christie MR, McConnell JM, Jansen EH, et al. Diet-induced obesity in female mice leads to offspring hyperphagia, adiposity, hypertension and insulin resistance: a novel murine model of developmental programming. Hypertension. 2008;51:383-92.

42. Nivoit P, Morens C, Van Assche FA, Jansen E, Poston L, Remacle $\mathrm{C}$, et al. Established diet-induced obesity in female rats leads to offspring hyperphagia, adiposity and insulin resistance. Diabetologia. 2009;52:1133-42.

43. Bayol SA, Simbi BH, Stickland NC. A maternal cafeteria diet during gestation and lactation promotes adiposity and impairs skeletal muscle development and metabolism in rat offspring at weaning. J Physiol. 2005;567:951-61.

44. Bayol SA, Farrington SJ, Stickland NC. A maternal 'junk food' diet in pregnancy and lactation promotes an exacerbated taste for 'junk food' and a greater propensity for obesity in rat offspring. $\mathrm{Br}$ J Nutr. 2007;98:843-51.

45. Bayol SA, Simbi BH, Bertrand JA, Stickland NC. Offspring from mothers fed a 'junk food' diet in pregnancy and lactation exhibit exacerbated adiposity that is more pronounced in females. J Physiol. 2008;586:3219-30.

46. Simar D, Chen H, Lambert K, Mercier J, Morris MJ. Interaction between maternal obesity and post-natal over-nutrition on skeletal muscle metabolism. Nutr Metab Cardiovasc Dis. 2012;22:269-76.

47. Plagemann A, Harder T, Kohlhoff R, Rohde W, Dörner G. Overweight and obesity in infants of mothers with long-term insulin-dependent diabetes or gestational diabetes. Int J Obes Relat Metab Disord. 1997;21:451-6.

48. Kirk SL, Samuelsson AM, Argenton M, Dhonye H, Kalamatianos $\mathrm{T}$, Poston L, et al. Maternal obesity induced by diet in rats permanently influences central processes regulating food intake in offspring. PLoS One. 2009;4:e5870.

49. Zhu MJ, Ma Y, Long NM, Du M, Ford SP. Maternal obesity markedly increases placental fatty acid transporter expression and fetal blood triglycerides at midgestation in the ewe. Am J Physiol Regul Integr Comp Physiol. 2010;299:R1224-31.

50. Zhu MJ, Du M, Nathanielsz PW, Ford SP. Maternal obesity upregulates inflammatory signalling pathways and enhances cytokine expression in the mid-gestation sheep placenta. Placenta. 2010;31:387-91.

51. Muhlhausler BS, Duffield JA, McMillen IC. Increased maternal nutrition stimulates peroxisome prolifertor activated recptor-gamma, adiponectin and leptin messenger ribonucleic acid expression in adipose tissue before birth. Endocrinology. 2007;148:878-85.

52. Odaka Y, Nakano M, Tanaka T, Kaburagi T, Yoshino H, Sato-Mito N, et al. The influence of a high-fat dietary environment in the fetal period on postnatal metabolic and immune function. Obesity. 2010;18:1688-94.

53. Farley D, Tejero ME, Comuzzie AG, Higgins PB, Cox L, Werner SL, et al. Feto-placental adaptations to maternal obesity in the baboon. Placenta. 2009;30:752-60. 
54. McCurdy CE, Bishop JM, Williams SM, Grayson BE, Smith MS, Friedman JE, et al. Maternal high fat triggers lipotoxicity in the fetal livers of non human primates. J Clin Invest. 2009;119:32335.

55. Plagemann A, Heidrich I, Götz F, Rohde W, Dörner G. Obesity and enhanced diabetes and cardiovascular risk in adult rats due to early postnatal over feeding. Exp Clin Endocrinol. 1992;99:154-8.

56. Patterson CM, Bouret SG, Park S, Irani BG, Dunn-Meynell AA, Levin BE. Large litter rearing enhances leptin sensitivity and protects selectively bred diet-induced obese rats from becoming obese. Endocrinology. 2010;151:4270-9.

57. Ozanne SE, Lewis R, Jennings BJ, Hales CN. Early programming of weight gain in mice prevents the induction of obesity by a highly palatable diet. Clin Sci. 2004;106:141-5.

58. Vickers MH, Breier BH, Cutfield WS, Hofman PL, Gluckman PD. Fetal origins of hyperphagia, obesity, and hypertension and postnatal amplification by hypercaloric nutrition. Am J Physiol Endocrinol Metab. 2000;279:E83-7.

59. Franke K, Harder T, Aerts L, Melchior K, Fahrenkrog S, Rodekamp E, et al. 'Programming' of orexigenic and anorexigenic hypothalamic neurons in offspring of treated and untreated diabetic mother rats. Brain Res. 2005;1031:276-83.

60. Lambin S, van Bree R, Caluwaerts S, Vercruysse L, Vergote I, Verhaeghe J. Adipose tissue in offspring of Lepr $(\mathrm{db} /+)$ mice: earlylife environment vs. genotype. Am J Physiol Endocrinol Metab. 2007;292:E262-71.

61. Shankar K, Harrell A, Liu X, Gilchrist JM, Ronis MJ, Badger TM. Maternal obesity at conception programs obesity in the offspring. Am J Physiol Regul Integr Comp Physiol. 2008;294:R528-38.

62. Shankar K, Kang P, Harrell A, Zhong Y, Marecki JC, Ronis MJ, et al. Maternal overweight programs insulin and adiponectin signalling in the offspring. Endocrinology. 2010;151:2577-89.

63. Srinivasan M, Mitrani P, Sadhanandan G, Dodds C, Shbeir-ElDika $\mathrm{S}$, Thamotharan S, et al. A high fat diet in the immediate postnatal life of rats induces adaptations predisposing to adult-onset obesity. J Endocrinol. 2008;197:565-74.

64. Akyol A, Langley-Evans SC, McMullen S. Obesity induced by cafeteria feeding and pregnancy outcome in the rat. Br $\mathrm{J}$ Nutr. 2009;102:1601-10.

65. Muhlhausler BS. Programming of the appetite-regulating neural network: a link between maternal overnutrition and the programming of obesity? J Neuroendocrinol. 2007;19:67-72.

66. Plagemann A. Perinatal nutrition and hormone-dependent programming of food intake. Horm Res. 2006;65:83-9.

67. Caron E, Sachot C, Prevot V, Bouret SG. Distribution of leptinsensitive cells in the postnatal and adult mouse brain. J Comp Neurol. 2010;518:459-76.

68. Davidowa H, Li Y, Plagemann A. Altered responses to orexigenic (AGRP, MCH) and anorexigenic (alpha-MSH, CART) neuropeptides of paraventricular hypothalamic neurons in early postnatally overfed rats. Eur J Neurosci. 2003;18:613-21.

69. Glavas MM, Kirigiti MA, Xiao XQ, Enriori PJ, Fisher SK, Evans $\mathrm{AE}$, et al. Early overnutrition results in early onset arcuate leptin resistance and increased sensitivity to high fat diet. Endocrinology. 2010;151:1598-610.

70. Bouret SG, Draper SJ, Simerly RB. Trophic action of leptin on hypothalamic neurons that regulate feeding. Science. 2004;304:10810 .

71. Bouret SG, Simerly RB. Development of leptin-sensitive circuits. J Neuroendocrinol. 2007;19:575-82.

72. Ahima RS, Prabakaran D, Flier JS. Postnatal leptin surge and regulation of circadian rhythm of leptin by feeding. Implications for energy homeostasis and neuroendocrine function. J Clin Invest. 1998;101:1020-7.

73. Cottrell EC, Cripps RL, Duncan JS, Barrett P, Mercer JG, Herwig A, Ozanne SE. Developmental changes in hypothalamic leptin receptor: relationship with the postnatal leptin surge and energy balance neuropeptides in the postnatal rat. Am J Physiol Regul Integr Comp Physiol. 2009;296:R631-9.

74. Proulx K, Richard D, Walker CD. Leptin regulates appetite-related neuropeptides in the hypothalamus of developing rats without affecting food intake. Endocrinology. 2002;143:4683-92.

75. Long NM, Ford SP, Nathanielisz PW. Maternal obesity eliminates the neonatal lamb plasma leptin peak. J Physiol. 2011;589:145562.

76. Stocker CJ, Wargent E, O'Dowd J, Cornick C, Speakman JR, Arch $J R$, et al. Prevention of diet-induced obesity and impaired glucose tolerance in rats following administration of leptin to their mothers. Am J Physiol Regul Integr Comp Physiol. 2007;292:R1810-8.

77. Sanchez J, Priego T, Palou M, Tobaruela A, Palou A, Picó C. Oral supplementation with physiological doses of leptin during lactation in rats improves insulin sensitivity and affects food preferences later in life. Endocrinology. 2008;149:733-40.

78. Ong ZY, Muhlhausler BS. Maternal "junk-food" feeding of rat dams alters food choices and development of the mesolimbic reward pathway in the offspring. FASEB J. 2011;25:2167-79.

79. Shelley P, Martin-Gronert MS, Rowlerson A, Poston L, Heales SJ, Hargreaves IP, et al. Altered skeletal muscle insulin signaling and mitochondrial complex II-III linked activity in adult offspring of obese mice. Am J Physiol Regul Integr Comp Physiol. 2009;297: R675-81.

80. Rattanatray L, MacLaughlin SM, Kleemann DO, Walker SK, Muhlhausler BS, McMillen IC. Impact of maternal periconceptional overnutrition on fat mass and expression of adipogenic and lipogenic genes in visceral and subcutaneous fat depots in the postnatal lamb. Endocrinology. 2010;151:5195-205.

81. Oben JA, Mouralidarane A, Samuelsson AM, Matthews PJ, Morgan ML, McKee C, et al. Maternal obesity during pregnancy and lactation programs the development of offspring non-alcoholic fatty liver disease in mice. J Hepatol. 2010;52:913-20.

82. Fraser A, Tilling K, Macdonald-Wallis C, Sattar N, Brion MJ, Benfield L, et al. Association of maternal weight gain in pregnancy with offspring obesity and metabolic and vascular traits in childhood. Circulation. 2010;121:2557-64.

83. Armitage JA, Lakasing L, Taylor PD, Balachandran AA, Jensen RI, Dekou V, et al. Developmental programming of aortic and renal structure in offspring of rats fed fat-rich diets in pregnancy. J Physiol (Lond). 2005;565:171-84.

84. Samuelsson AM, Morris A, Igosheva N, Kirk SL, Pombo JM, Coen $\mathrm{CW}$, et al. Evidence for the sympathetic origins of hypertension in juvenile offspring of obese rats. Hypertension. 2010;55:7682.

85. Rudyk O, Makra P, Jansen E, Shattock MJ, Poston L, Taylor PD. Increased cardiovascular reactivity to acute stress and salt-loading in adult male offspring of fat fed non-obese rats. PLoS One. 2011;6:e25250. Epub 2011 Oct 17.

86. Cerf ME, Chapman CS, Muller CJ, Louw J. Gestational high-fat programming impairs insulin release and reduces Pdx-1 and glucokinase immunoreactivity in neonatal Wistar rats. J Metabol Clin Exp. 2009;58:1787-92.

87. Rkhzay Jaf JM, Kepczynska MA, Wargent ET, Hislop DC, Cawthorne MA, Arch JRS, et al. Developmental programming of pancreatic tissue by maternal high fat feeding. Diabetologia. 2011;54:S204.

88. Zhang L, Long NM, Hein S. Maternal obesity in ewes results in reduced fetal pancreatic $\beta$-cell numbers in late gestation and decreased circulating insulin concentration at term. Domest Anim Endocrinol. 2011;40:30-9.

89. • Ng SF, Lin RCY, Laybutt DR, Barres R, Owens JA, Morris MJ. Chronic high fat diet in fathers programs beta cell dysfunction in female rat offspring. Nature 2010;467:963-6. Rodent study highlighting paternal inheritance of the metabolic syndrome on islet 
cell function. Study highlights the potential importance of transmission of epigenetic patterns in the sperm genome. Should be read in conjunction with reference 99.

90. Radaelli T, Varastehpour A, Catalano P, Hauguel-de Mouzon S. Gestational diabetes induces placental genes for chronic stress and inflammatory pathways. Diabetes. 2003;52:2951-8.

91. Yan X, Zhu MJ, Xu W, Tong JF, Ford SP, Nathanielsz PW, et al. Upregulation of Toll-like receptor 4/nuclear factor kappaB signalling is associated with enhanced adipogenesis and insulin resistance in fetal skeletal muscle of obese sheep at late gestation. Endocrinology. 2010;151:380-7.

92. - Sen S, Simmons RA. Maternal antioxidant supplementation prevents adiposity in the offspring of western diet-fed rats. Diabetes 2010;59:3058-65. Rodent study highlighting impact of Vitamin $A, C$ and $E$ on the attenuation of offspring susceptibility to metabolic disease as a result of maternal obesity.

93. Igosheva N, Abramov AY, Poston L, Eckert JJ, Fleming TP, Duchen MR, et al. Maternal diet-induced obesity alters mitochondrial activity and redox status in mouse oocytes and zygotes. PLoS One. 2010;5:e10074.

94. Bruce KD, Cagampang FR, Argenton M, Zhang J, Ethirajan PL, Burdge GC, et al. Maternal high-fat feeding primes steatohepatitis in adult male offspring, involving mitochondrial dysfunction and altered lipogenesis gene expression. Hepatology. 2009;50:1796808.

95. - andovici I, Smith NH, Nitert MD, Ackers-Johnson M, UribeLewis $\mathrm{S}$, Ito $\mathrm{Y}$ et al. Maternal diet and aging alter the epigenetic control of a promoter-enhancer interaction at the Hnf4alpha gene in rat pancreatic islets. Proc Natl Acad Sci USA. 2011;108:544954. Seminal paper showing the impact of methylation patterns in the developmental programming of the rat islet.

96. Waterland RA, Garza C. Early postnatal nutrition determines adult pancreatic glucose-responsive insulin secretion and islet gene expression in rats. J Nutr. 2002;132:357-64.

97. Plagemann A, Harder T, Brunn M, Harder A, Roepke K, WittrockStaar M, et al. Hypothalamic proopiomelanocortin promoter methylation becomes altered by early overfeeding: an epigenetic model of obesity and the metabolic syndrome. J Physiol. 2009;587:496376.

98. El-Osta A, Brasacchio D, Yao D, Pocai A, Jones PL, Roeder RG, et al. Transient high glucose causes persistent epigenetic changes and altered gene expression during subsequent normoglycemia. J Exp Med. 2008;205:2409-17.

99. Dunn GA, Bale TL. Maternal high fat diet effects in third generation female body size via the paternal lineage. Endocrinology. 2011;152:2228-36. 